\title{
A Avaliação no Sistema Educacional Brasileiro: Um resgate historiográfico
}

\author{
Ronaldo Bezerra dos Santos ${ }^{1}$
}

\begin{abstract}
Resumo: Inicialmente tratar-se-á do objeto de estudo deste artigo - avaliação externa no sistema educacional brasileiro, sua importância, seus fundamentos, sua aplicabilidade, o que não impede que se trate de forma introdutória, na verdade um resumo historiográfico, do percurso da educação brasileira, com ênfase nas inúmeras reformas ao longo dos anos que se seguem desde a sua introdução no território brasileiro, a cargo dos padres jesuítas - portanto um início de cunho confessional - alcançando as duras medidas empreendidas pelo Primeiro Ministro português Marquês de Pombal, que culminaram com a expulsão daqueles sacerdotes dos domínios da Coroa portuguesa, seguindo-se um breve período da estada da família real no Brasil, observando-se as medidas engendradas por el-rei de Portugal D. João VI, de características até certo ponto descentralizadoras, adentrando no período imperial, em cujas ações dos imperadores reflete-se o pouco caso com a educação voltada para os súditos pobres do império, e finalmente desembocando na República, visualizando um pouco de cada uma de suas fases: República Velha, onde a educação sempre esteve relegada a segundo plano, e a política era o principal assunto nas rodas sociais; República ditatorial e populista de Vargas, com pouca descentralização e maior atenção ao ensino técnico-profissionalizante; República do regime ditatorial militar, promovendo a racionalização da educação, principalmente universitária, para impedir a coesão para a subversão; e por fim uma introdução superficial na fase de redemocratização, do país, a partir de 1985, alcançando todos os ex-presidentes, com um levantamento rápido sobre suas reformas no sistema educacional brasileiro.
\end{abstract}

Palavras-Chave: Educação. República. Governo. Reforma. Sistema Educacional

\section{The Evaluation in the Brazilian Educational System: A historiographic rescue}

\begin{abstract}
Initially, this article will be the object of study of this article - external evaluation in the Brazilian educational system, its importance, its fundamentals, its applicability, which does not prevent that it is an introductory form, in fact a historiographic summary, of the course of Brazilian education, with emphasis on the numerous reforms that have been carried out over the years since its introduction into Brazilian territory, by the Jesuit priests - thus a beginning of confessional - reaching the harsh measures undertaken by the Portuguese Prime Minister Marquês de Pombal, Which culminated in the expulsion of these priests from the Portuguese Crown, following a brief period of the royal family's stay in Brazil, observing the measures engendered by the King of Portugal, D. João VI, with characteristics that were to some extent decentralizing, Entering the imperial period, whose actions of the emperors reflect the little case with the education directed to the poor subjects of the empire, and finally ending up in the Republic, visualizing a little of each one of its phases: Old Republic, where the education Has always been relegated to the background, and politics was the main issue on the social wheels; Dictatorial and populist republic of Vargas, with little decentralization and greater attention to technical-vocational education; Republic of the military dictatorial regime, promoting the rationalization of education, mainly university, to prevent cohesion for subversion; And finally a superficial introduction in the re-democratization phase of the country, starting in 1985, reaching all former presidents, with a fast survey of their reforms in the Brazilian educational system.
\end{abstract}

Keywords: Education. Republic. Government. Reform. Educational system

\footnotetext{
${ }^{1}$ Licenciado em Historia - URCA - Especialista em Historia e Sociologia - URCA - Mestrando em Educação - Programa de Mestrado Internacional Anne Sullivan University. E-mail: profronaldo62@ hotmail.com
} 
Id on Line Revista Multidisciplinar e de Psicologia

Id on Line Multidisciplinary and Psycology Journal

\section{Introdução}

O processo de avaliação em larga escala dentro do sistema público educacional brasileiro é algo recente. O seu início data dos anos 90, a partir da criação do Sistema Nacional de Avaliação da Educação Básica (Saeb). Inicialmente envolveu apenas alunos dos $1^{\circ}, 3^{\circ}, 5^{\circ} \mathrm{e}$ $7^{\mathbf{o}}$ anos do Ensino Fundamental, abrangendo as disciplinas Língua Portuguesa, Matemática e Ciências. Nos $5^{\circ}$ e $6^{\circ}$ anos, também foi avaliada a Produção Textual. Esse processo inicial foi feito por amostragem de escolas. Em 1995 as avaliações foram dirigidas aos alunos das $4^{\mathrm{a}}$ e $8^{\mathrm{a}}$ séries do Ensino Fundamental (hoje $5^{\circ}$ e $9^{\circ}$ anos) e $3^{\circ}$ ano do Ensino Médio. Entre 2001 e 2013 incluiu-se a disciplina de Ciências para os alunos da $8^{\mathrm{a}}$ série $/ 9^{\circ}$ ano do Ensino Fundamental e $3^{\circ}$ ano do Ensino Médio, o que se deu em caráter experimental. A reestruturação do Saeb, em 2005, levou o MEC a diagnosticar, por amostra, escolas das redes pública e privada através da Avaliação Nacional da Educação Básica (Aneb) e da Prova Brasil, esta a cada dois anos e somente para a rede pública, em escolas com no mínimo 30 alunos matriculados na última etapa dos anos iniciais ( $4^{\mathrm{a}}$ série $/ 5^{\mathrm{o}}$ ano) ou dos anos finais ( $8^{\mathrm{a}}$ série $/ 9^{\circ}$ ano) do Ensino Fundamental.

Visando uma melhoria no seu sistema de ensino através de avaliações diagnósticas, alguns estados foram estimulados a implementar sistemas de avaliação, como é o caso dos estados do Ceará e de São Paulo, que criaram o Sistema Permanente de Avaliação da Educação Básica do Ceará (Spaece) e o Sistema de Avaliação do Rendimento Escolar do Estado de São Paulo respectivamente. (AVALIA EDUCACIONAL, 2016).

O descaso pelo qual tem passado a educação no Brasil, desde a sua introdução no território brasileiro, obra dos jesuítas sob a égide da Coroa portuguesa, passando pelo período imperial, seguido do republicano, encontra-se refletido hoje na situação caótica em que se encontra a nossa educação e, consequentemente, tem instigado os gestores a por em prática medidas através das quais buscam corrigir os erros, as omissões, cometidos no passado, como é ocaso das avaliações externas. Sem sombra de dúvida, tais medidas têm sido de grande valia no diagnóstico de deficiências das mais variadas formas. Contudo, também se faz necessário que se verifiquem determinadas normas de cunho estrutural, contidas, por exemplo, na LDB, cuja observação, juntamente com aquelas medidas diagnósticas, forma um conjunto relevante na solução de problemas detectados. 
Id on Line Revista Multidisciplinar e de Psicologia

Id on Line Multidisciplinary and Psycology Journal

\section{Resumo Historiográfico das Avaliações em Larga Escala}

A década de 1980 marcou, para o Brasil, a ruptura histórica, da sociedade com o regime de governo militar autoritário, processo cuja denominação, redemocratização, bem o caracteriza, pois esta lhe foi peculiar. Assim como nas mais diversas áreas da sociedade civil se ansiava por abertura, por democracia, liberdade, respeito aos direitos, também na educação se fizeram ouvir as vozes dos que, há muito, reclamavam por um ensino de qualidade, que viesse contemplar a todos indistintamente, universalmente. Foi nesse clima de mudança que começaram a surgir os primeiros projetos de avaliação educacional em larga escala, que, curiosamente, foram alavancados por agências transnacionais, projetos estes que viriam a se converter mais tarde num dispositivo de avaliação de alcance nacional, o SAEB (Sistema de Avaliação da Educação Básica).

Poucos anos depois, na década de 90, fatores como o aprofundamento do neoliberalismo, da globalização, o avanço das tecnologias da comunicação e da informação, e da interferência em massa de órgãos transnacionais, mudaram o cenário mundial passando a exigir dos Estados uma postura mais comprometedora com a educação. No Brasil, o Estado assume essa responsabilidade a partir da promulgação da $2^{\mathrm{a}}$ Lei de Diretrizes e Bases da Educação Nacional (LDB), Lei 9394/96.

Em síntese e resgatando a historia, pode-se afirmar que, desde a Constituição Federal de 1988, passando pelas sucessivas Medidas Provisórias, pela LDB de 96, pelo Plano Nacional de Educação e por vários Decretos, constata-se um avanço no desenvolvimento e implementação de políticas de avaliação em larga escala para aferição quantitativa e qualitativa da Educação Nacional. (OLIVEIRA e ROCHA, 2007).

Nesse contexto a educação brasileira passa a contar com dispositivos criados pelo Estado, cujo objetivo está voltado exclusivamente para a possibilidade de se ampliar a percepção da situação da educação brasileira com o intuito de oferecer-lhe suporte para a sua melhoria, tanto na qualidade quanto na quantidade. Os próprios dispositivos são passíveis de redimensionamento ou redirecionamento, caso se verifique sua necessidade. 
Id on Line Revista Multidisciplinar e de Psicologia

Id on Line Multidisciplinary and Psycology Journal

\section{Avaliações Externas no Brasil: Buscando a Qualidade?}

O sistema de ensino educacional brasileiro, assim como acontece em vários países do mundo, é frequentemente submetido a exames cuja finalidade é fazer um levantamento diagnóstico das reais condições em que se encontra em termos de ensino-aprendizagem.

\footnotetext{
Não há País no mundo preocupado em aumentar a eficiência, a equidade e a qualidade do seu sistema educacional que tenha ignorado a importância da avaliação como mecanismo de acompanhamento dos processos de reforma. Cada vez mais atribui-se relevância tanto à avaliação institucional em suas diferentes dimensões (condições da infraestrutura das instituições escolares; processos de gestão; formação, qualificação e produtividade dos recursos humanos, etc.), como em relação à avaliação de resultados (o que e como os alunos aprendem, quais os fatores associados ao rendimento escolar, impactos de fatores extra e intra-escolares na aprendizagem, etc.). (CASTRO, 1998)
}

Como se pode observar, a busca pela qualidade na educação não implica apenas na observação, através de avaliação de nível de proficiência, de fatores diretamente ligados ao rendimento escolar, como conteúdos, por exemplo, mas abrange uma gama de motivos nos quais subjaz parte dos resultados obtidos por aquela avaliação.

Diante das preocupações com a obtenção de resultados positivos, necessário se faz que indaguemos, no caso da educação pública do Brasil, acerca de determinadas situações pertinentes a esse conjunto de informações: Esse sistema de avaliação é também direcionado, existe nele um viés, para questões que levem em conta o lado social do alunado, as razões do abandono escolar, da repetência, da disparidade acentuada entre a faixa etária e o ano escolar, da desmotivação de boa parte dele, da baixa assiduidade verificada? Que medidas são tomadas com relação aos problemas constatados?

\section{O que fazer com os resultados das Avaliações Externas?}

Os diagnósticos, logicamente, sempre apresentam algum resultado. Evidentemente que esse resultado deverá servir de parâmetro para a tomada de medidas que visem a solução dos problemas detectados. No campo educacional tem se observado mudanças periódicas nos processos de avaliação externa, o que nos leva a acreditar que ainda não se conseguiu atingir o 
modelo ideal desse tipo de avaliação (GONÇALVES e OLIVEIRA, 2016). Por conseguinte, os resultados esperados estão sempre oscilando, ora deixando a desejar ora atingindo patamares que beiram o satisfatório.

A relevância da avaliação reside nas possibilidades e oportunidades que se abrem quando utilizamos seus resultados na orientação das políticas educacionais para a garantia e ampliação do direito a uma educação de qualidade para todos. Como disse anteriormente, o uso dos dados obtidos com as avaliações de sistemas pode (e deve!) ir muito além da classificação, do ranking. Por essa razão, esse é o debate mais importante em torno da avaliação, sem desmerecer outras etapas que, com certeza, têm peso preponderante na construção dos processos avaliativos. (MACHADO, 2011).

Sem querer-se usar de redundância, mas por força da relevância do assunto aqui contextualizado, reitera-se a importância da avaliação no sentido de que se persiga, a todo custo, a implementação das mudanças, quando necessárias, reclamadas pelos resultados obtidos, aí sim, quando concretizadas essas mudanças, terá sido alcançado o verdadeiro objetivo da avaliação em larga escala.

\section{Objetivos do Brasil para a Educação, em Números}

Embora tenhamos experimentado um crescimento considerável no que diz respeito aos números em termos de educação, o Brasil ainda apresenta resultados aquém daqueles apresentados por alguns países, inclusive, vizinhos nossos, na mesma América, como é o caso da Argentina $\left(27^{\mathrm{a}}\right)$, do Chile $\left(37^{\mathrm{a}}\right)$, da Venezuela $\left(64^{\mathrm{a}}\right)$ e o Peru $\left(65^{\mathrm{a}}\right)$.

(...) Em relação ao compromisso Educação para Todos, firmado em 2000, entre 129 países avaliados, o Brasil aparece na $76^{\mathrm{a}}$ posição, o pior ranking da América do Sul (...).

O país corre o risco de não atingir sequer três dos seis objetivos estabelecidos mundialmente na ocasião, com metas até 2015, a fim de melhorar a qualidade da educação, desde o ensino fundamental até a universidade. No ápice da pirâmide, encontram-se 51 países, uma vez que eles já atingiram esses objetivos ou estão prestes a atingi-los, ao passo que, na parte de baixo, 25 países, entre eles a Índia, o Paquistão e países africanos provavelmente não conseguirão alcançar tais objetivos. (QUEIROZ, 2015). 
Id on Line Revista Multidisciplinar e de Psicologia

Id on Line Multidisciplinary and Psycology Journal

É realmente gritante a situação de descaso com o sistema educacional, pela qual passam determinados países, alguns desde a sua concepção, como é o caso do Brasil, que já apresenta deficiências a partir da sua introdução com os membros da Companhia de Jesus, passando pelo império, e agora na república.

Um assunto que sempre preocupou aqueles que realmente defendem uma educação de qualidade e universal, são os investimentos direcionados pelo Estado com base no PIB (Produto Interno Bruto). Os países melhor colocados no ranking destinam um percentual de modo a garantir o funcionamento pleno e eficaz da educação, qualidade e quantidade estão sempre em pauta, daí se verificar que fatores como saúde, segurança, lazer, transporte, habitação e outros, funcionam a ponto de proporcionar à coletividade uma melhor qualidade de vida. O Brasil não investe pouco com relação ao seu PIB, é verdade, já se investiu bem menos num passado não distante, não obstante, o problema é que se invista melhor, outrossim, que se valorize mais o profissional da educação, que se leve em conta também as questões de infraestrutura escolar, a qualidade da merenda escolar. Infelizmente o nosso país ainda vive a cultura da corrupção, do desvio, da barganha, do levar vantagem em tudo, e isso concorre diretamente para a situação atual. A educação precisa de reforma no seu sistema, mas não só ela, a reforma deve atingir também determinados “conceitos" na sociedade.

Se observarmos a tabela que se segue, transcrita do blog do jornalista Reinaldo Azevedo, na página eletrônica da Revista Veja, de 04 de junho de 2014, verificaremos, estupefatos, que países considerados de primeiro mundo chegam a investir menos que o nosso em educação. Assim concluímos: o nosso problema não é quanto investir, mas como investir. Não é a quantidade dele, mas a sua qualidade.

\begin{tabular}{l|l|l|l}
\hline Ranking & País & Gasto com educação & Posição no pisa \\
\hline 1 & Islândia & $7,80 \%$ & $16^{\circ}$ lugar \\
\hline 2 & Noruega & $7,30 \%$ & $12^{\circ}$ lugar \\
\hline 3 & Suécia & $7,30 \%$ & $19^{\circ}$ lugar \\
\hline 4 & Nova Zelândia & $7,20 \%$ & $7^{\circ}$ lugar \\
\hline 5 & Finlândia & $6,80 \%$ & $3^{\circ}$ lugar \\
\hline 6 & Bélgica & $6,60 \%$ & $11^{\circ}$ lugar \\
\hline 7 & Irlanda & $6,50 \%$ & $21^{\circ}$ lugar \\
\hline
\end{tabular}


Id on Line Revista Multidisciplinar e de Psicologia

Id on Line Multidisciplinary and Psycology Journal

\begin{tabular}{l|l|l|l}
\hline 8 & Estônia & $6,10 \%$ & $13^{\circ}$ lugar \\
\hline 9 & Argentina & $6 \%$ & $58^{\circ}$ lugar \\
\hline 10 & Áustria & $6 \%$ & $39^{\circ}$ lugar \\
\hline 11 & Holanda & $5,90 \%$ & $10^{\circ}$ lugar \\
\hline 12 & França & $5,90 \%$ & $22^{\circ}$ lugar \\
\hline 13 & Israel & $5,90 \%$ & $37^{\circ}$ lugar \\
\hline 14 & Portugal & $5,80 \%$ & $27^{\circ}$ lugar \\
\hline $\mathbf{1 5}$ & Brasil & $\mathbf{5 , 7 0 \%}$ & $\mathbf{5 3}^{\circ}$ lugar \\
\hline 16 & Eslovênia & $5,70 \%$ & $31^{\circ}$ lugar \\
\hline 17 & Reino Unido & $5,60 \%$ & $25^{\circ}$ lugar \\
\hline 18 & Suíça & $5,50 \%$ & $14^{\circ}$ lugar \\
\hline 19 & Estados Unidos & $5,50 \%$ & $17^{\circ}$ lugar \\
\hline 20 & México & $5,30 \%$ & $48^{\circ}$ lugar \\
\hline
\end{tabular}

Reforma por reforma... as várias reformas executadas no Sistema Educacional Brasileiro pelos vários governos

\section{Reforma na Administração Pombalina}

Não há dúvida de que o sistema educacional brasileiro reclama por reformas urgentemente e há muito tempo, o que não significa dizer que toda e qualquer reforma seja benvinda. Existem parâmetros que devem norteá-las, e esses parâmetros devem ser consequência de um estudo minucioso, o que vem sendo feito através das avaliações externas.

Reformas na educação brasileira nós as temos desde a intervenção de Sebastião José de Carvalho e Melo, o Marquês de Pombal, Primeiro Ministro português, no governo de D. José. Em suas medidas, imbuídas do despotismo esclarecido, que, aliás, culminam com a expulsão dos padres jesuítas do território brasileiro, subjazem os indícios daquela que é considerada a primeira reforma no sistema educacional. De acordo com Azevedo (1976), podem-se interpretar tais medidas como sendo a iniciativa do governo português para promover a emancipação "do ensino público da influência pedagógica dos jesuítas". 
O Estado que não intervinha na gestão das escolas elementares e secundárias, tomou a seu cargo, por iniciativa de Pombal, a função educativa que passou a exercer, em colaboração com a Igreja, aventurando-se a um largo plano de oficialização do ensino. (AZEVEDO, P. 50, 1976).

Como parte dessa reforma pombalina o Estado passa a centralizar as ações educativas com a criação do cargo de Diretor de Estudos, e cria a Real Mesa Censória com a finalidade de cuidar dos negócios da educação. Essa mesma Mesa Real Censória as "Escolas Menores", sob sua inspeção. Em 1772 o currículo passa ter nova configuração com o "funcionamento de 15 aulas de gramática latina, 3 de língua grega, 6 de retórica e 3 de filosofia racional, sendo despachados 15 docentes de Lisboa para o Brasil”. (VIEIRA e FARIAS, 2007, p. 41).

\section{Família Real no Brasil: Descentralização da Educação}

Durante a estada da família real no Brasil, a reforma observada foi apenas a descentralização do ensino elementar e secundário, estes ficando a cargo das províncias, e por conta da Coroa apenas o ensino superior, cujos cursos teriam sido recém-criados por iniciativa da própria Coroa, e a educação básica, "ministrada no Município da Corte." (VIEIRA e FARIAS, 2007, p. 43).

\section{Primeiro Reinado: Abertura à Iniciativa Privada e um Ensaio para a LDB}

No decorrer dos trabalhos da Constituinte de 1823, portanto, durante o primeiro período imperial, a reforma aprovada através de lei dizia respeito ao "princípio da liberdade de ensino sem restrições." (AZEVEDO, 1976, p. 72). Na prática " a todo cidadão era facultado o direito de criar escola elementar, sem que para isso tivesse que enfrentar os requerimentos legais de autorização, licença e exame.” (VIEIRA e FARIAS, 2007, p. 57 ).

A Lei de 15 de outubro de 1827 é considerada por alguns estudiosos como sendo um ensaio da LDB que passaria a vigorar anos mais tarde no país. 
Esta Lei era o que resultara do projeto de Januário da Cunha Barbosa, (1826) onde estavam presentes as idéias de educação como dever do Estado, da distribuição racional por todo o território nacional das escolas dos diferentes graus e da necessária graduação do processo educativo. Dele (projeto) vigorou simplesmente a idéia de distribuição racional por todo território nacional mas apenas das escolas de primeiras letras, o que equivale à uma limitação quanto ao grau (só um) e quanto aos objetivos de tal grau (primeiras letras). (Ribeiro, p. 2000).

Além de determinar que "em todos as cidades, villas e logares mais populosos haveriam as escolas de primeiras letras que forem necessárias" (Art. $1^{\circ}$ ), esta lei também regulamenta uma série de outras medidas. Contém dispositivos que definem desde o método de ensino a ser adotado - ensino mútuo (Art. $4^{\circ}$ ) - até a previsão de formas de provimento de professores. (Art. $7^{\circ}, 8^{\circ}$ e 14), ordenados (Art. $3^{\circ}$ ) e capacitação (Art. $5^{\circ}$ ). Também apresenta determinações sobre edifícios escolares (Art. $5^{\circ}$ ), assim como a criação de "escolas de meninas nas cidades e villas mais populosas" (Art. 11) e os respectivos conteúdos do ensino a ministrar em tais instituições (Art. 12). (VIEIRA e FARIAS, 2007, p. 59).

Referida lei seria o início da organização educacional popular no país, porém, estava fadada ao fracasso, pois as suas determinações não correspondiam às verdadeiras intenções do governo.

\section{Segundo Reinado: Reformas Nem Sempre Significam Mudança}

Em 1854 os ensinos primário e secundário do Município da Corte são regulamentados através do Decreto 1.331A, de 17 de fevereiro de 1854, chamado de Reforma Couto Ferraz; os estatutos dos Cursos Jurídicos passam a ter nova definição através do Decreto 1.386, de 28 de abril de 1854 (Reforma Luiz Pedreira); entre os anos 1878 e 1879 a Reforma Leôncio de Carvalho cria, através dos Decretos 7.031A, de 6 de setembro de 1878 e 7.247, de 19 de abril de 1879, a alfabetização de adultos no turno noturno, nas escolas públicas do Município da Corte e reforma o ensino primário e secundário no Município da Corte e o superior em todo o Império respectivamente.

Levando em consideração que apenas $10 \%$ da população brasileira naquele período tinha acesso às instituições escolares, não se pode negar que a educação, apesar de todas as reformas, continuava sendo um privilégio de nobres.

Limiar do Período Republicano (1889-1930): Agitação no Cenário Político. E a Educação? 
O advento da República é marcado por um cenário político efervescente. A ruptura definitiva com o antigo regime só acontece de fato anos mais tarde. Entre 1889 e 1930, vários acontecimentos têm lugar na sociedade: disputas pelo poder central, conflitos sociais e movimentos messiânicos (Guerra de Canudos, Guerra do Contestado, Revolta da Vacina, Padre Cícero), movimentos de insurreição (Revolta da Chibata, os dezoito do Forte Copacabana, rebelião militar de 1924, Coluna Prestes), tentativa de implantação do anarquismo, lutas operárias apoiadas pelos recém-criados sindicatos, entre outros. Toda essa agitação sóciopolítica-econômica deságua na Revolução de 1930. A educação, não obstante a mudança na forma de governo, em nada havia mudado no sentido de alcance universal e qualidade.

\footnotetext{
Ninguém tinha interesse em se alfabetizar, o interesse maior era em viver, brincar e trabalhar, mas, em todo caso, as famílias de classe média botavam os filhos na escola (...) Era um ensino muito rudimentar, era apenas o ensino das primeiras letras, depois a silabação e então a leitura... Depois havia ainda a tabuada que era uma espécie de aritmética inicial. A gente aprendia cantando. As escolas se transformavam numa espécie de escola de canto. (CORDEIRO, 1996, p. 132-133).
}

A citação acima é o relato de um morador de Fortaleza, à época, que retrata a infância naqueles anos iniciais do século XX. A política e, por conseguinte, a economia, experimentam novas circunstâncias, a educação, porém, em nada se modifica.

\section{Reformas na Velha República - Resumo Historiográfico}

Apesar de todo aquele fervilhar de ideias, de agitação social, envolvendo todas as classes sociais que compunham a sociedade brasileira à época, como vimos a educação não logrou uma mudança, uma guinada, que significasse realmente um avanço nas suas estruturas, na sua base. Contudo, o conturbado período da chamada República Velha, foi pródigo na concessão de reformas educacionais, o que mostra que havia o interesse de algumas pessoas em pensar uma educação reformada, apesar de que nem sempre essas reformas corresponderam aos anseios da sociedade. Senão vejamos:

- 1890 - Reforma Benjamin Constant, que trazia em seu bojo vários decretos: Decreto n ${ }^{\circ}$ 981, de 08 de novembro de 1890, que regulamentava a Instrução Primária e Secundária do Distrito Federal; Decreto ${ }^{\circ}$ 1075, de 22 de novembro de 1890, que criava o regulamento para 
Id on Line Revista Multidisciplinar e de Psicologia

Id on Line Multidisciplinary and Psycology Journal

o Ginásio nacional; Decreto $\mathrm{n}^{\circ} 1232-\mathrm{G}$, de 02 de janeiro de 1891, que criava e aprovava o Regulamento do Conselho de Instrução Superior;

- 1898-1902 - Reforma Epitácio Pessoa, que através do Decreto 3890, de 01 de janeiro de 1901, aprova o Código de Institutos Oficiais de Ensino Superior e Secundário; Decreto 3914, de 26 de janeiro de 1901, que trata do Regulamento para o Ginásio Nacional;

- 1910-1914 - Reforma Rivadávia Corrêa, aprovada pelo Decreto 8659, de 05 de abril de 1911, que aprovou Lei Orgânica do Ensino Superior e do Ensino Fundamental na República; Decreto 8660, de 05 de abril de 1911, que criou o Regulamento do Colégio Pedro II;

- 1914-1918 - Reforma Carlos Maximiliano, que sob o Decreto 11530, de 18 de março de 1915, reformou o ensino secundário e regulamentou o superior na República; (Vieira; Farias, 2007);

- Reforma João Luis Alves (Decreto n 16782-A, de 13 de janeiro de 1925, também conhecida como Lei Rocha Vaz ou Luis Alves Rocha Vaz. Esta proposta realizada no governo de Artur Bernardes (1922-1926), organiza o Departamento Nacional de Ensino e reforma o ensino secundário e superior, além de outras providências. (...). (ROMANELLI, 2002);

Essa gama de reformas executadas durante a primeira fase da República traduz os anseios de intelectuais da época, mas sua realização na prática não se traduz em dados concretos tão ansiosamente aguardados.

\section{Educação na Era Vargas: Indícios de Centralização}

Passada a fase da Primeira República (1889-1930), inaugura-se no Brasil a chamada Era Vargas(1930-1945). A Revolução de 1930, articulada pelos tenentes, chega ao seu auge com a deposição do presidente Washington Luiz e o impedimento da posse do Eleito Júlio Prestes. Vargas, que deveria assumir provisoriamente o governo, permanece por um período de 15 anos, durante os quais é manifesta a sua maneira ditatorial e populista de governar.

As reformas operadas durante esse período revelam o caráter centralizador, que será um reflexo da expressão da política do governo Vargas. Vejamos as reformas;

- 1931 - Reforma Francisco Campos, engendrada pelo Decreto n 19.851 , de 11 de abril de 1931. Através deste Decreto adota-se o regime universitário para o ensino superior, 
Id on Line Revista Multidisciplinar e de Psicologia

Id on Line Multidisciplinary and Psycology Journal

estrutura-se o ensino comercial, cria-se a função de Inspetor Escolar; Decreto ${ }^{\circ}$ 19.890, de 18 de abril de 1931, que "dispõe sobre a organização do ensino secundário"; Decreto n 21.241 , de 4 de abril de 1932, consolidou a divisão do ensino secundário em duas etapas: o curso fundamental, com duração de 5 anos, obrigatório para a admissão em qualquer escola superior; e o complementar, de caráter propedêutico e com 2 anos de duração, tendo por objetivo, a “adaptação às futuras especializações profissionais". (Ribeiro, 2000, p. 107);

- 1942-1946 - Reforma Gustavo Capanema, representada pelas chamadas Leis Orgânicas do Ensino, em cuja vigência entram em ação a Lei Orgânica do Ensino Industrial, pelo Decreto-lei no 4.073, de 30 de janeiro de 1942; pelo Decreto-lei $n^{\circ} 4.244$, de 9 de abril de 1942, Lei Orgânica do Ensino Secundário, o ensino secundário; e o Decreto-lei n ${ }^{\circ} 6.141$, de 28 de dezembro de 1943, Lei Orgânica do Ensino Comercial, que institui o ensino secundário.

\begin{abstract}
Após a queda de Vargas, em 1945, seriam apresentadas medidas relativas ao ensino fundamental (Lei Orgânica do Ensino Primário- Decreto-lei no 8.529, de 2 de janeiro de 1846), ao ensino normal (Lei Orgânica do Ensino Normal - Decreto-lei $n^{\circ} 8.530$, de 2 de janeiro de 1946) e ao ensino agrícola (Lei Orgânica do Ensino Agrícola Decreto-lei 9.623, de 20 de agosto de 1946). Também é instituído o Serviço Nacional de Aprendizagem Comercial (SENAC - Decretos-leis 8.621 e 8.622, de 10 de janeiro de 1946); (...) e o Serviço Nacional de Aprendizagem Industrial (SENAI), criado pelo Decreto-lei ${ }^{\circ}$ 4.048, de 22 de janeiro de 1942, dirigido e mantido pela Confederação Nacional das Indústrias. (VIEIRA e FARIAS, 2007, p. 99-100).
\end{abstract}

Saliente-se aqui a característica profissionalizante que teve a educação no governo Vargas, com ênfase no ensino técnico-profissional.

Naquele ano de 1946 passa a tramitar no Congresso Nacional o projeto de Lei de Diretrizes e Bases da Educação.

Do ponto de vista da educacional os obstáculos pelos quais passou o projeto de Lei de Diretrizes e Bases da educação Nacional (LDBEN) acabaram por gerar uma significativa campanha em favor da escola pública.

É interessante relatar as "marchas e contra-marchas" da LDBEN até ser transformada na Lei $n^{\circ} 2.024 / 61$, porque é uma evidência a mais sobre a resistência dos setores dominantes contra uma organização educacional, voltada para os interesses do conjunto da população. (...) Em 1959 o Manifesto dos Educadores, redigido por Fernando de Azevedo e assinado por 189 pessoas, deixava claro o sentido do ensino público, obrigatório e gratuito, evidenciando o aspecto social da educação e conclamando o Estado a assumir seu dever mantenedor do sistema escolar. (XAVIER, RIBEIRO e NORONHA, 1994, p. 176-177-178). 
Id on Line Revista Multidisciplinar e de Psicologia

Id on Line Multidisciplinary and Psycology Journal

Entre idas e vindas esse projeto inicial é arquivado por iniciativa do deputado Gustavo Capanema, antigo Ministro da Educação. Em 1957, dá-se o desarquivamento e reconstituição do mesmo. Finalmente em 1961, com a interferência do então deputado Carlos Lacerda, favorável ao privativismo, acontece a sua aprovação, cujo teor se volta mais favoravelmente ao ensino privado que aquele organizado e assumido pelo Estado.

\section{Reforma Educacional nos Anos de Chumbo}

Durante os anos do regime ditatorial, diante da crescente insatisfação da classe estudantil e sua mobilização contra a repressão

Tanto o processo escolar brasileiro quanto as reformas e o ideário pedagógico desse passavam por um processo de "tecnicização" e de "expansão controlada". O lema dominante era": reformar para desmobilizar, preparando o jovem para o desenvolvimento do país. (XAVIER, RIBEIRO e NORONHA, 1994, p. 235).

Esse lema ia de encontro aos objetivos dos repressores à medida que objetivava conter as ações aglutinadoras dos estudantes que tentavam a todo custo mobilizar a sociedade civil contra o regime militar. Uma da medidas para a desmobilização foi a elaboração das leis $\mathrm{n}^{\circ}$ 5.540/68 e no 5.692/71, (Reforma do Ensino Superior e Reforma do Ensino de $1^{\circ}$ e $2^{\circ}$ graus respectivamente.

\footnotetext{
A proposta racionalizadora da lei $\mathrm{n}^{\circ} 5.540 / 68$, manifestou-se na departamentalização, na instituição do ciclo básico, na unificação do vestibular, na matrícula por disciplina (sistema de créditos) e na criação de cursos de curta duração em contraposição aos anseios de autonomia da universidade proposta pelos estudantes. (XAVIER, RIBEIRO e NORONHA, 1994, p. 236).
}

Na prática significava isolamento dos discentes, pois suas turmas estariam separadas até o final do curso, e dos docentes, que estariam isolados em seus departamentos. A coesão com finalidades políticas estaria, assim, dificultada.

Durante o governo Ernesto Geisel, dezembro de 1974, foi publicado o II Plano Nacional de Desenvolvimento (PND), (1975-1979), contendo a lei no 5.692/71 "completando o ciclo de reformas que tinha como propósito ajustar a política educacional à "estabilidade" 
Id on Line Revista Multidisciplinar e de Psicologia

Id on Line Multidisciplinary and Psycology Journal

desmobilizadora e excludente empreendida de 1964 em diante”. Através daquela lei o Estado manifestava seus planos voltados para uma ideologia de desenvolvimento obrigatoriamente profissionalizante a cargo da educação. As escolas particulares foram exitosas no cumprimento dessa lei em vista dos recursos disponíveis, enquanto que as escolas públicas ficaram a mercê dos recursos do Estado que não chegavam.

\section{A Educação na Onda da Redemocratização}

Findado o período ditatorial com a eleição indireta do presidente Tancredo Neves, o Brasil passa a viver a expectativa de mudanças há muito ansiadas pelos mais diversos setores da sociedade. Durante os governos democráticos da chamada "Nova República" as ações governamentais se voltam com mais veemência para a área econômica.

O Governo José Sarney - No governo Sarney, tendo assumido por morte de Tancredo Neves, a ênfase é para a elaboração da nova Constituição que iria reger os rumos do país, a partir de 1988, ano da sua promulgação, conhecida como "Constituição Cidadã".

O Governo Fernando Collor de Mello - No governo Fernando Collor a palavra de ordem é privatização. Através de suas ações procura combater os altos salários na esfera federal e promover a abertura à competição internacional. Não completando seu mandato por ocasião do Impeachment, assume o vice Itamar franco, cuja preocupação com as dificuldades pelas quais passam os setores econômicos, lança mão do Plano Cruzado, criando a nova moeda (Real).

O Governo Fernando Henrique Cardoso - O governo Fernando Henrique Cardoso, que ocupou dois mandatos (1995-2003), não explicita de imediato suas intenções para com a educação no País, apesar de a educação figurar como umas cinco metas de seu governo. Somente a partir de 1996 seus planos vêm as claras. Através de mudança na redação do Ato das Disposições Constitucionais Transitórias (Art. 60 da Constituição Federal). 


\begin{abstract}
As alterações visam: permitir a intervenção da União nos Estados, caso estes não apliquem o valor mínimo exigido por lei (Art. 34); rever o dever do Estado na oferta e ensino fundamental para os que a ele não tiveram acesso em idade própria e de ensino médio (Art. 26); definir as responsabilidades das diferentes esferas do Poder Público em relação à oferta de ensino (Art. 211); detalhar os recursos aplicados pela União na erradicação do analfabetismo e na manutenção do ensino fundamental (Art. 212); e, prever a criação de fundo de natureza contábil, para a manutenção e desenvolvimento do ensino fundamental e valorização de seu magistério (ADCT, Art. 60). (VIEIRA E FARIAS, 2007, p. 166-167).
\end{abstract}

Embora tímidas são medidas animadoras após um longo período de jejum em que se esperava que a educação tivesse uma atenção mais imediata desde que se passou a viver a onda de redemocratização. Passados alguns meses a Lei no 9.394, de 20 de dezembro de 1996, que estabelece as Diretrizes e Bases da Educação Nacional, entra em vigor, acompanhada logo em seguida pela Lei $n^{\circ}$ 9.424, de 24 de dezembro de 1996, Lei do FUNDEF, finalmente o que mais se esperava, a tomada de medidas com relação aos investimentos na área ocorreu. Na realidade a LDB, cuja nomenclatura inicial era LDBEN, já havia sido promulgada desde 1961, o que se seguia agora era um aperfeiçoamento, com uma maior abrangência. O FUNDEF (Fundo de Manutenção e Desenvolvimento do Ensino Fundamental e de Valorização do Magistério), teria duração de dez anos, a partir de 1998. Ainda durante a gestão Fernando Henrique são concebidos o Sistema Nacional de Avaliação da Educação Básica (SAEB) e o Exame Nacional do Ensino Médio (ENEM). O currículo escolar passa por reforma a partir da proposta que cria os Parâmetros Curriculares Nacionais (PCNs). Programas como o PNAE (Programa Nacional de Alimentação escolar), PNLD (Programa Nacional do Livro Didático), PDDE (Programa Dinheiro Direto na Escola, o PROINFO (Programa Nacional de Informática na Educação) e o PROFORMAÇÃO (Programa de Formação de Professores em Exercício) são fortalecidos, consolidados e ampliados.

O Governo Lula - Assim como em governos anteriores, de acordo com estudiosos no assunto, também foram acanhadas as medidas adotadas com relação à educação no governo do presidente Luiz Inácio da Silva (Lula), quando se sabe que são bem maiores as necessidades e mais amplas as possibilidades. Apesar disso se reconhece que na comparação com aqueles as políticas educacionais tiveram uma maior atenção.

O governo Lula, na área de educação, desenvolveu programas, estabeleceu parcerias com os municípios e diretamente com as escolas, algumas vezes sem interferência dos 
estados, estabelecendo um novo modelo de gestão de políticas públicas e sociais. (Portal-Educação, 2013).

Observe-se que na realidade esse novo modelo de gestão de políticas públicas adotado no governo Lula já havia sido inaugurado no Governo FHC, seu antecessor, Lula apenas o incrementou e fomentou pelo País. Registre-se que no último ano do seu primeiro mandato o presidente Lula dá uma nova redação ao parágrafo $5^{\circ}$ do Art. 212 da Constituição Federal e ao Art. 60 do Ato das disposições Constitucionais Transitórias criando o Fundo de Manutenção e Desenvolvimento da Educação básica e de Valorização dos profissionais da Educação (FUNDEB), uma nova versão do FUNDEF. Vale salientar ainda a criação de programas com o intuito de facilitar o ingresso dos estudantes em diversos cursos universitários em todo o Brasil e até no exterior: Sisu, ProUni, Pronatec, Ciência sem Fronteira, Fies.

\section{Considerações Finais}

A trajetória do sistema de ensino público no Brasil apresenta, desde a sua implantação, situações que explicitam da maneira mais clara possível o desinteresse reinante por parte daqueles que diretamente seriam responsáveis pelo seu sucesso ou insucesso: as autoridades governamentais. A eles cabem o ônus e o bônus pelos resultados obtidos, em vista de serem os guardiões do bem estar da sociedade, bem estar de cuja essência também faz parte a educação.

Em meio a cenários políticos os mais variados, conturbados e oscilantes, sobressai uma educação pública fragilizada, um sistema educacional público caracterizado pela carência de uma melhor atenção e de mais zelo.

Não sem tempo grupos de verdadeiros baluartes acorrem em seu socorro e intercedem em seu favor prolongando-lhe os últimos suspiros, trazendo a tona os resquícios do que ainda resta para fazê-la ressurgir.

Já são passados pouco mais de 500 anos de história do nosso país, faltam poucos anos para o bicentenário da nossa independência, somos um país relativamente novo, contudo as nossas instituições já parecem cansadas, a nossa República, com apenas 127 anos, já nasceu velha, carcomida por histórico de desmandos das mais diversas formas em todos os poderes constituídos durante a Colônia e também no Império. 
Id on Line Revista Multidisciplinar e de Psicologia

Id on Line Multidisciplinary and Psycology Journal

A nossa instabilidade político-econômico-financeira gerada por esse histórico acaba por refletir no sistema educacional direcionando-o para o caos, e aquele, ao mesmo tempo, passa a reivindicar mudanças, reformas, que se sucedem, como estratégia de superação e sobrevivência. Mudanças e reformas que na maioria das vezes se dão de maneira pífia, acanhada, superficial, que refletem a falta de interesse em encarar o problema de frente com o intuito de combater seus verdadeiros males.

\section{Referência Bibliográfica}

AZEVEDO, Fernando de. A transmissão da cultura: a cultura brasileira. São Paulo: Melhoramentos; Brasília: INL, 1976

AZEVEDO, Reinaldo. Investimento de $10 \%$ em educação não passa de uma caríssima demagogia barata; sem uma profunda reforma no sistema haverá só aumento da ineficiência; o Brasil já gasta uma fábula na área. Disponível em: $<$ http://veja.abril.com.br/blog/reinaldo/geral/investimento-de-10-do-pib-em-educacao-naopassa-de-uma-carissima-demagogia-barata-sem-uma-profunda-reforma-do-sistema-havera-soaumento-da-ineficiencia-brasil-ja-gasta-uma-fabula-na-area/>. Acesso em: 22 mai. 2016.

CASTRO, Maria Helena Guimarães de. Avaliação do Sistema Educacional Brasileiro. Tendências $e$ Perspectivas. Disponível em: <www.dominiopublico.gov.br/download/texto/me000110.pdf >. Acesso em 17 mai. 2016

GONÇALVES, A.C.O.L.; OLIVEIRA, R.T.P. Avaliação docente em questão: tendências e estratégias. Id on Line Revista de Psicologia, Set-Out., vol.10, n.31, Supl 2, p. 291-304, 2016.

MACHADO, Cristiane. Politicas Públicas. Avaliar as escolas para que? Disponível em: $<$ http://revistaeducacao.uol.com.br/textos/169/artigo234947-1.asp>. Acesso em: 17 mai. 2016

OLIVEIRA, Maria Auxiliadora Monteiro; ROCHA, Glady. Avaliação em Larga Escala no Brasil nos Primeiros Anos do Ensino Fundamental. Disponível em: <www.anpde.or.br/congresso_antigos/simposio2007/274.pdf>. Acesso em 19 mai.2016

QUEIROZ, Roberto. A Educação Brasileira: o pior ranking da América do Sul. Recanto das Letras. Disponível em: <www.recantodasletras.com.br/artigos/97inado1303>. Acesso em: 19 mai. 2016

ROMANELLI, Otaiza de Oliveira. História da Educação no Brasil: 1930-1973. 27 ed. Petrópolis: Editora Vozes, 2002. 
VIEIRA, Sofia Lerche; Albuquerque, Maria Glaucia Menezes. estrutura e funcionamento da educação básica. Fortaleza: Edições Demócrito Rocha, UECE, 2001. 144p.

VIEIRA, Sofia Lerche; Farias, Isabel Maria Sabino de. Política Educacional no Brasil introdução histórica. Brasília: Liber Livro Editora, 2007, 188p.

XAVIER, Maria Elisabete; Ribeiro, Maria Luisa; Noronha, Olinda Maria. História da Educação - A escola no Brasil. São Paulo: FTD, 1994. - Coleção Aprender \& Ensinar.

Avaliação Educacional. EDUCACIONAL, Avalia. Disponível em: <www.avaliaeducacional.com.br/avaliação/>. Acesso em: 17 mai. 2016

Educação nos 8 anos de Lula. Disponível em: <http://www.inesc.org.br/noticias/noticiasgerais/2011/janeiro/educacao-nos-8-anos-de-lula>. Acesso em: 23 mai. 2016

Políticas Educacionais Para Educação Básica no Governo de luiz I. Lula da Silva. Disponível em: <http://www.portaleducacao.com.br/pedagogia/artigos/43199/politicas-educacionaispara-educacao-basica-no-governo-de-luiz-i-lula-da-silva>. Acesso em: 23 mai. 2016

\section{Como citar este artigo (Formato ABNT):}

SANTOS, Ronaldo B. A Avaliação no Sistema Educacional Brasileiro: Um Resgate Historiográfico. Id on Line Revista Multidisciplinar e de Psicologia, Fevereiro de 2017, vol.11, n.34, p. 46-63. ISSN: 1981-1179.

Recebido: 04.10.2016

Aceito: 06.02.2017 